\title{
openheart From randomised controlled trial to real world implementation of a novel home- based heart failure tool: pooled and comparative analyses of two clinical controlled trials
}

\author{
Ann Hovland-Tånneryd, ${ }^{1}$ Michael Melin, ${ }^{2}$ Ewa Hägglund, ${ }^{2}$ Inger Hagerman, ${ }^{2}$ \\ Hans E Persson ${ }^{3}$
}

To cite: Hovland-Tånneryd A, Melin M, Hägglund E, et al. From randomised controlled trial to real world implementation of a novel home-based heart failure tool: pooled and comparative analyses of two clinical controlled trials. Open Heart 2019;6:e000954. doi:10.1136/ openhrt-2018-000954

Received 19 0ctober 2018 Revised 21 March 2019 Accepted 6 May 2019

\section{Check for updates}

(c) Author(s) (or their employer(s)) 2019. Re-use permitted under CC BY-NC. No commercial re-use. See rights and permissions. Published by BMJ.

${ }^{1}$ Hemse Health Central, Region Gotland, Visby, Sweden ${ }^{2}$ Heart and Vascular Theme, Karolinska Universitetssjukhuset Stockholm, Sweden

${ }^{3}$ Department of Clinical Sciences, Danderyd Hospital, Karolinska Institutet, Stockholm, Sweden

Correspondence to Dr Ann Hovland-Tånneryd, Hemse Health Central, Region Gotland, 62351 Hemse,

Sweden; ann.hovlandtanneryd@gotland.se

\section{ABSTRACT}

Objectives A home-based tool for heart failure (HF) patients, was evaluated in a specialist setting as a randomised controlled trial (RCT) and also in a validation cohort in a primary care setting in a clinical controlled trial (CCT). The tool provides education, symptom monitoring and titration of diuretics. The aim of this study was thus to extend validity of the previous RCT findings in order to describe applicability of the tool in clinical practice. Methods Data from both trials were analysed separately, as well as a pooled data set $(n=172)$. Data were analysed with respect to HF related in-hospital days, self-care behaviour and system adherence, during a 6-month intervention. The analysis of in-hospital days for the pooled data was adjusted for baseline differences between the two study cohorts, relating to disease state.

Results In the RCT ( $n=72$ ) the intervention group (IG) consisted of 32 patients and the control group (CG) of 40 patients. The risk ratio (RR) for in-hospital days was RR: $0.72,95 \% \mathrm{Cl} 0.61$ to $0.84, p<0.05$ in favour of the IG. In the CCT $(n=100)$ both the IG and the CG consisted of 50 patients and the IG had fewer in-hospitals days, comparable to the RCT findings with RR: $0.67 ; 95 \% \mathrm{Cl} 0.45$ to $0.99 ; p<0.05$. For the pooled data set made up of 172 patients, the groups were well balanced but with a higher prevalence of hypertension in the CG. The RR relating to in-hospital days for the pooled data set was $0.71 ; 95 \% \mathrm{Cl}$ 0.61 to $0.82 ; p<0.05$ in favour of the IG. There was a statistically significant improvement in self-care by $27 \%$ and the median system adherence was $94 \%$.

Conclusions These analyses suggest that the evaluated tool might reduce $\mathrm{HF}$ related in-hospital days in the general HF population, which adds to the external validity of previous findings.

Clinical Trial Registration

NCT03655496.

\section{INTRODUCTION}

According to the WHO, eHealth is the use of information and communication technologies for health, and with the wide spread of mobile technologies, a new field of eHealth

\section{Key questions}

What is already known about this subject?

- The need to digitalise appropriate parts of healthcare is evident, and the investigated mHealth tool has previously been studied in a small randomised controlled trial (RCT).

What does this study add?

- New technical solutions often fail to leave the test bed-environment to be implemented in clinical practice and oftentimes the reason can be that the generalisability, or external validity of the RCTfindings is questioned. This study aims to compare the RCT findings to the more pragmatic design of a validation project in primary care, and to also analyse the two data sets together.

How might this impact on clinical practice?

- The investigators hope to provide healthcare professionals and healthcare organisations a better foundation for assessing the potential use of the investigated mHealth tool as a part of clinical practice.

has emerged, called mHealth. mHealth, is a component of eHealth, a medical health practice supported by mobile devices. ${ }^{1}$ WHO predicts that the emergence of mHealth will transform health services and it will have an important role to play in combating disease.

Heart failure (HF) remains a huge burden to western countries with a prevalence in the general population of $2 \%-3 \%^{2}$ and consuming $1 \%-2 \%$ of the total healthcare expenditure in industrialised countries. ${ }^{3} 4$ With an ageing population it is estimated that HF will increase in prevalence. $^{5}$ Approximately $70 \%-80 \%$ of HF costs are attributed to hospitalisations which always are signs of deterioration and adds to the burden for the HF patient. ${ }^{467}$ Therefore, it 
seems relevant to address the issue of consumption of hospital HF care.

It has been suggested that telemonitoring might be a feasible way of keeping patients out of the hospital but so far, the results are not conclusive. ${ }^{8}$ In the light of these findings it is important to confirm that mHealth interventions do in fact work, before spending large scale resources.

Clinical trials can be described as either explanatory or pragmatic, depending on whether the design is optimised for internal or external validity. ${ }^{9}$ A randomised controlled trial (RCT) is the best study design to evaluate the effect of an intervention, but randomisation alone does not offer any knowledge as to whether the findings are generalisable beyond the precise situation in which the trial was done. ${ }^{10}$ In contrast, pragmatic trials are aimed at studying the intervention under routine clinical practise situations. ${ }^{11}$

Another important aspect when studying HF is to remember that as more patients are being diagnosed with HF, most patients will present themselves in primary care, so the role of the general practitioner is becoming increasingly important. ${ }^{12}$ In Sweden, most HF-patients are elderly and treated in primary care. ${ }^{13}$ To properly evaluate the efficacy of a proposed HF intervention, it may be appropriate to evaluate efficacy both in an RCT and in a routine clinical practise, preferably in some way including primary care.

A novel, home-based mHealth-tool for HF patients (OPTILOGG) has been evaluated with positive results in an RCT in Stockholm, Sweden, incorporating three cardiology clinics in the study PACEMAN-HF. ${ }^{15}$ The same HF-tool was later evaluated in primary care in a rural region of Sweden (the Hemse study) and presented at the European Society of Cardiology's (ESC) HF-congress in Florence, Italy in 2016. ${ }^{16}$

The aim of this study was to use data from both data sets and use the pooled data to analyse the effect of the intervention on in-hospital days, in order to produce results with greater external validity.

\section{METHODS \\ Design \\ PACEMAN-HF}

In the parallel RCT PACEMAN-HF, study subjects were recruited before discharge after an acute HF-admission to the hospital, with three participating centres in Stockholm, Sweden. ${ }^{1415}$ To be eligible to participate in the study, patients needed to be diagnosed with HF and be over 18 years old. Exclusion criteria were a life-expectancy of less than 6 months, or cognitive impairment of such severity as it would make the patient unable to understand instructions provided. Recruited patients were randomised 1:1 to an intervention group (IG) or control group (CG). The blinded data analyst created three separate sets of sealed envelopes with $50 \%$ of each set of envelopes containing allocation to the IG, and the other $50 \%$ allocation to the CG. Each set of the sealed envelopes were delivered to each recruiting centre, where an envelope was drawn and opened after the patient had submitted his/her consent and completed the baseline data acquisition, by the recruiting nurse. Every patient, regardless of group allocation, received written information on appropriate self-care behaviour, as well as a direct telephone number to a HF nurse, that they could contact in case of worsening symptoms or concern. The intervention lasted for 180 days.

\section{Hemse}

In the Hemse-study, the same exclusion and inclusion criteria were applied, based on learnings from PACEMAN-HF. The duration of the intervention was also kept the same, to make the pooled analysis more straightforward. The most important difference was that all study subjects were being treated in primary care and in a rural part of Sweden, whereas the study subjects in PACEMAN-HF were recruited at hospitals in Stockholm, the capital of Sweden. The Hemse study was a pragmatic, quasi-randomised 1:1, parallel controlled clinical trial and eligible patients were those with a confirmed HF diagnoses and complete echocardiography examination, listed at the Hemse Health Central (HHC) at the time of the study. The purpose of the echocardiography examination was to further increase probability that all patients included had HF and had not been previously misdiagnosed. Another important difference was that none of the patients in PACEMAN-HF were referred to an outpatient HF clinic, whereas the HHC has a HF clinic in-house which all eligible patients attended. Optimised recommended medical treatment and self-care education were given according to current guidelines. ${ }^{17}$

\section{Sample}

In PACEMAN-HF, the recruited patients constituted $10 \%$ of patients admitted to the recruiting hospitals during the time of enrolment. Consecutive sampling was employed, as the responsible healthcare provider (HCP) at the respective clinic approached patients as they were close to being discharged. Patients who were referred to the outpatient HF clinic following the discharge were not eligible to participate in the study. A total of 82 patients were recruited between February and June of 2013, and out of these 10 withdrew consent before ever being exposed to the intervention. ${ }^{15}$

At the time of enrolment to the Hemse-study, 114 patients were listed at the HHC with a diagnosis of HF. Out of these patients 14 either failed to meet all inclusion criteria or met one or more exclusion criteria and 100 were eligible to participate. Instead of employing formal sampling and formal randomisation, since it was desired to emulate standard practise as much as possible in the interest of external validity, 50 of these patients were simply assigned to the IG by randomly selecting them from the list of patients. These patients were prescribed the mHealth-tool as part of their HF treatment, and the 
remaining 50 constituted the CG and were subject to standard care.

\section{Intervention}

The mHealth-tool consists of a specialised tablet computer wirelessly connected to a weight scale, which is installed in the patient's home. It contains an adaptive education module to better the patient's understanding of $\mathrm{HF}$ as well as enhancing their self-care behaviour. It also contains a titration module for diuretics, where the patient's sudden weight changes are used as input. When a patient is prescribed the mHealth-tool, certain patient-specific parameters are put in by the patient's treating physician, to set the limits for the diuretics and then the mHealth-tool titrates the dose based on the patient's weight changes, as proposed in the ESC guidelines valid at the time of the study. ${ }^{17}$ The tool also registers three of the patient's self-reported symptoms, namely shortness of breath, fatigue and peripheral swelling/ oedema. Based on an algorithm utilising the data from the weights, dose of diuretics, the self-reported symptoms and the patient's interaction with the mHealth-tool, it can automatically detect a deterioration in HF status and alert for a high risk of an imminent exacerbation. If the mHealth-tool detects such a deterioration in HF status, the patient will be alerted on screen. The alert contains a brief summary of what has happened and contact information to the HCP, and the instruction to contact the HCP. For the Hemse study, care was taken to make the introduction of the intervention as much like standard practice as possible, where the allocated patients were recommended the tool by their treating physician.

\section{Outcomes and data collection}

In both studies, data regarding patients' hospitalisations was retrieved from the medical records and adjudicated as HF-related or not by the responsible physician. The data analyst performed the analysis on blinded data for both the separate data sets from the two studies, and the pooled data set. This outcome was specifically chosen to fulfil the aim of the study which was to add to the generalisability of the findings. Different regions have implemented different strategies in combating HF and certain strategies lead to increased re-admissions but shorter length-of-stay (LOS), whereas others may lead to a decrease in re-admissions at the cost of increased LOS. The choice of assessing in-hospital days was made as it is likely most relevant both to the payer and the patient and should also serve to make the interpretation of the results more general.

A secondary outcome of this study was the patient's adherence to the tool (system compliance), stratified by age, gender and place of residence. Another secondary outcome was self-care behaviour, as assessed by the European Heart Failure Self-care Behaviour Scale (EHFScB9 ), which is a validated tool for measuring self-care behaviour. ${ }^{18}$ For budget reasons, the EHFScB-9 was only collected for intervention patients in the Hemse-study. All outcomes were assessed 180 days after randomisation.

\section{Sample size and statistical analyses}

In PACEMAN-HF, the sample-size calculations resulted in that $30+30$ patients would be required to reject the null hypotheses with $80 \%$ power, and a type-I error probability of $5 \% .^{14}$

Retrospectively, it was noted that the 72 recruited patients were enough to detect a statistically significant difference in days spent at the hospital, and that number was used when deciding on the sample-size for the Hemsestudy, with some additional considerations.

We estimated that the Hemse-population would be better treated, since all participants had attended an outpatient HF-clinic, but that they would likely display poorer self-care behaviour as a larger proportion of the participants would be from a rural area. ${ }^{19}$ Using the methodology proposed by Li et al and the adjusted data from the PACEMAN-HF trial as input, we would need $45+45$ patients in order to reject the null hypothesis with $80 \%$ power. ${ }^{20}$ Therefore, the target for enrolment was set at $25 \%$ higher than in the PACEMAN-HF study, that is, 90 patients.

For consistency reasons, the statistical methodology was fully adopted from the analyses used in PACEMAN-HF. ${ }^{1415}$ The baseline characteristics were analysed using the $\chi 2$ test and a t-test for independent samples. Hospital days per patient and 180 days were analysed using generalised Poisson log-linear regression. Due to the two cohorts being different in terms of disease level, and therefore having different baseline risk, the regression model was made to include an interaction term to adjust for these differences. In both studies we were interested in estimating the net/marginal incidence rate ratio of inpatient hospitalisation, so absorbing competing events (eg, death) were handled by censoring. The selfcare behaviour (EHFScB-9) was analysed using the Mann-Whitney U test. The effect on system adherence by different factors was analysed with multiple linear regression. $\mathrm{P}$ values of less than 0.05 were considered statistically significant and all tests were two-tailed. All patients who did not explicitly withdraw their consent were included in the analyses and all patients in the IG equipped with the mHealth-tool were included, irrespective if they returned the mHealth-tool prior to the follow-up or not. All statistical calculations were performed in R, V.3.0.1.

\section{RESULTS}

\section{Patients and baseline characteristics}

The participant flow is shown in figure 1. From PACEMAN-HF study, complete data from 72 patients recruited during 4 months and followed for 180 days were available (IG: 32, CG: 40). One hundred patients (IG: 50, CG: 50) were recruited in the Hemse study, which was more than the required sample-size, but a more pragmatic design means it is more likely that we experience 


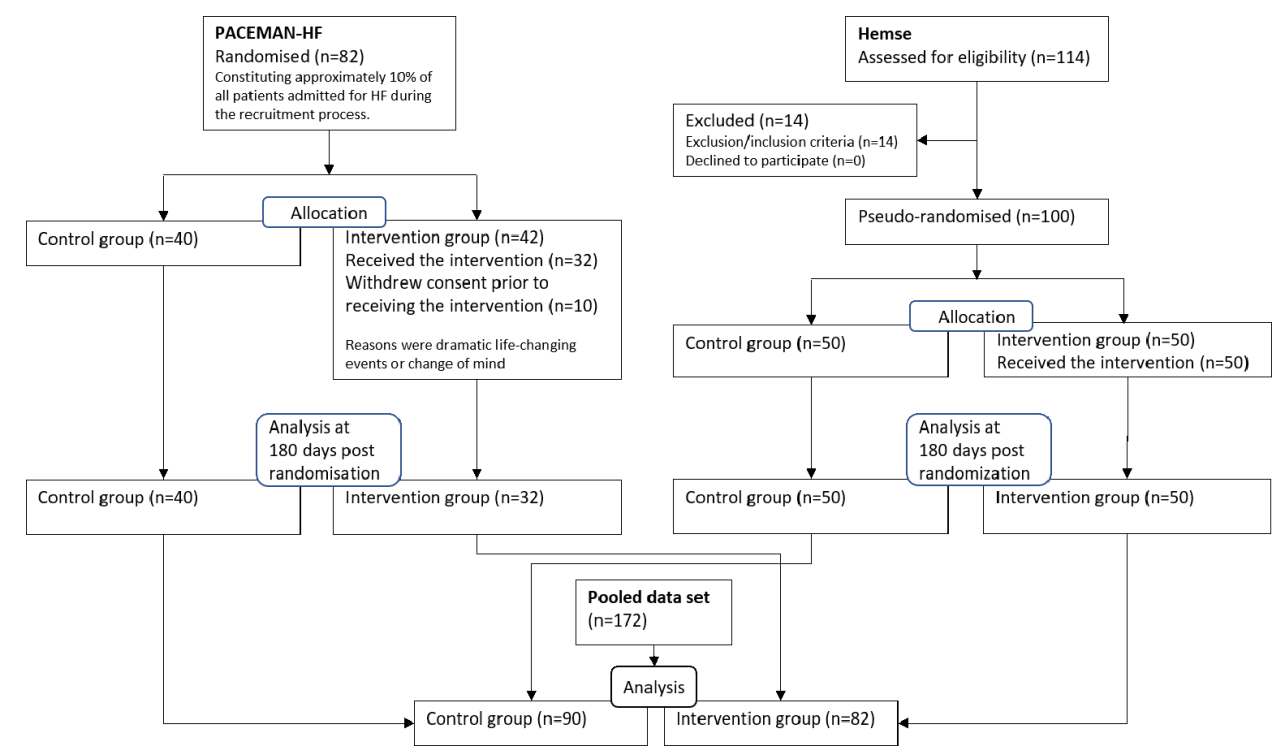

Figure 1 Participant flow.

higher attrition, so the excess recruitment was deemed motivated. ${ }^{21}$ These patients were analysed separately and combined according to groups, such that the IG was 82 patients and the CG was 90 patients. The groups were well balanced after randomisation, both in the separate study cohorts (see tables 1 and 2) and in the combined data set (see table 3).

In the PACEMAN-HF data set, there were significantly more patients in the CG with atrial fibrillation, but this difference disappeared in the pooled data set.

\begin{tabular}{lllll}
\hline $\begin{array}{l}\text { Table } 1 \\
\text { study }\end{array}$ & Clinical & \multicolumn{3}{l}{ characteristics at baseline for the Hemse } \\
\hline Hemse & All & IG & $\mathbf{C G}$ & $\mathbf{P}$ \\
$\mathbf{n = 1 0 0}$ & $\mathbf{n = 5 0}$ & $\mathbf{n = 5 0}$ & value \\
\hline Male gender & 65 & 70 & 60 & n.s. \\
\hline Age (mean \pm SD) & $78 \pm 9$ & $77 \pm 9$ & $78 \pm 9$ & n.s. \\
NYHA I & 9 & 6 & 12 & n.s. \\
NYHA II & 48 & 48 & 48 & \\
NYHA III & 43 & 46 & 40 & \\
\hline Atrial fibrillation & 57 & 62 & 52 & n.s. \\
\hline Diabetes mellitus & 31 & 38 & 24 & n.s. \\
\hline COPD & 13 & 16 & 10 & n.s. \\
\hline Hypertension & 43 & 26 & 60 & $<0.05$ \\
\hline CAD & 29 & 34 & 24 & n.s. \\
\hline Beta-blockers & 93 & 98 & 88 & n.s. \\
\hline RAS-blockade & 93 & 96 & 90 & n.s. \\
\hline MRA & 37 & 40 & 34 & n.s. \\
\hline
\end{tabular}

All numbers presented as per cent unless otherwise noted. CAD, coronary artery disease; CG, control group; COPD, chronic obstructive pulmonary disease; IG, intervention group; MRA, mineralocorticoid receptor antagonist; NYHA, New York Heart Association; RAS-blockade, renin-angiotensin system blockade (angiotensin converting enzyme inhibitor or angiotensin receptor blocker); n.s., non-significant.
In the Hemse data set, there were significantly more patients in the CG with hypertension (HTN) and this difference persisted in the pooled data set (see table 3 ). There was also a significant difference in the prescription of beta-blockers between the groups, with $98 \%$ in the IG compared with $88 \%$ in the CG, with an average of $92 \%$ for all patients. On average, $85 \%$ were prescribed renin-angiotensin system (RAS)-blockade and $34 \%$ were prescribed mineralocorticoid receptor antagonists, with no significant differences between the two groups. The

Table 2 Clinical characteristics at baseline for the PACEMAN-HF study

\begin{tabular}{lllll}
\hline PACEMAN-HF & $\begin{array}{l}\text { All } \\
\mathbf{n = 7 2}\end{array}$ & $\begin{array}{l}\text { IG } \\
\mathbf{n = 3 2}\end{array}$ & $\begin{array}{l}\mathbf{C G} \\
\mathbf{n = 4 0}\end{array}$ & $\begin{array}{l}\mathbf{P} \\
\text { value }\end{array}$ \\
\hline Male gender & 68 & 66 & 70 & n.s. \\
\hline Age (mean \pm SD) & $75 \pm 8$ & $75 \pm 8$ & $76 \pm 7$ & n.s. \\
NYHA I & 0 & 0 & 0 & \\
\hline NYHA II & 26 & 38 & 18 & n.s. \\
NYHA III & 74 & 63 & 83 & \\
\hline Atrial fibrillation & 61 & 47 & 73 & p<0.05 \\
\hline Diabetes mellitus & 40 & 34 & 45 & n.s. \\
\hline COPD & 18 & 13 & 23 & n.s. \\
\hline Hypertension & 50 & 56 & 45 & n.s. \\
\hline CAD & 29 & 28 & 30 & n.s. \\
Beta-blockers & 92 & 97 & 88 & n.s. \\
RAS-blockade & 74 & 69 & 78 & n.s. \\
\hline MRA & 31 & 31 & 30 & n.s. \\
\hline
\end{tabular}

All numbers presented as per cent unless otherwise noted. CAD, coronary artery disease; CG, control group; COPD, chronic obstructive pulmonary disease; IG, intervention group; MRA, mineralocorticoid receptor antagonist; NYHA, New York Heart Association; RAS-blockade, renin-angiotensin system blockade (angiotensin converting enzyme inhibitor or angiotensin receptor blocker); n.s., non-significant. 


\begin{tabular}{|c|c|c|c|c|}
\hline Pooled & $\begin{array}{l}\text { All } \\
n=172\end{array}$ & $\begin{array}{l}\text { IG } \\
n=82\end{array}$ & $\begin{array}{l}\text { CG } \\
n=90\end{array}$ & $\begin{array}{l}P \\
\text { value }\end{array}$ \\
\hline Male gender & 66 & 68 & 64 & n.s. \\
\hline Age (mean $\pm S D)$ & $77 \pm 8$ & $76 \pm 8$ & $77 \pm 8$ & n.s. \\
\hline NYHA I & 5 & 4 & 7 & n.s. \\
\hline NYHA II & 39 & 44 & 34 & \\
\hline NYHA III & 56 & 52 & 59 & \\
\hline Atrial fibrillation & 59 & 56 & 61 & n.s. \\
\hline Diabetes mellitus & 35 & 37 & 33 & n.s. \\
\hline COPD & 15 & 15 & 16 & n.s. \\
\hline Hypertension & 46 & 38 & 53 & $<0.05$ \\
\hline CAD & 29 & 32 & 27 & n.s. \\
\hline Beta-blockers & 92 & 98 & 88 & $<0.05$ \\
\hline RAS-blockade & 85 & 85 & 84 & n.s. \\
\hline MRA & 34 & 37 & 32 & n.s. \\
\hline
\end{tabular}

All numbers presented as per cent unless otherwise noted. CAD, coronary artery disease; CG, control group; COPD, chronic obstructive pulmonary disease; IG, intervention group; MRA, mineralocorticoid receptor antagonist; NYHA, New York Heart Association; RAS-blockade, renin-angiotensin system blockade (angiotensin converting enzyme inhibitor or angiotensin receptor blocker); n.s., non-significant.

distribution of patients according to New York Heart Association (NYHA) class was 5\% NYHA I, 39\% NYHA II and $56 \%$ NYHA III with no significant difference between the IG and the CG. The distribution of NYHA-classes between the two cohorts, however, was significantly different with a higher prevalence of NYHA III in the PACEMAN-HF and conversely a higher prevalence of NYHA-classes I and II in the Hemse-cohort $(\mathrm{p}<0.01)$.

\section{Outcomes}

In-hospital days

During the intervention period, seven patients died in the $\mathrm{CG}$ and four in the IG, but the results were non-significant (n.s.). There was a total of 960 hospital days registered for the patients during the 180 days, out of which 706 were adjudicated as HF-related, with 261 in the IG and 445 in the CG, that is, a total difference of 184 days (see figure 2). This corresponds to 3.2 days per patient in the IG and 4.9 in the $\mathrm{CG}$, or a reduction by $36 \%$, corresponding to 1.8 in-hospital days fewer per patient in the IG, at 180 days. The analysis was then adjusted for the fact that the patients in the Hemse-cohort were healthier. The adjusted log-linear regression yields a risk ratio (RR) of RR: $0.71 ; 95 \%$ CI 0.61 to $0.82 ; \mathrm{p}<0.05$, equivalent to a reduction by $29 \%$. The corresponding results cohort by cohort was RR: $0.67 ; 95 \%$ CI 0.45 to $0.99 ; \mathrm{p}<0.05$ for the Hemse-study (a reduction from 1.2 to 0.8 days per patient and 180 days) and RR: $0.72,95 \%$ CI 0.61 to $0.84, \mathrm{p}<0.05$ for PACEMAN-HF (corresponding to a reduction from 9.6 to 6.9 days per patient and 180 days). The unadjusted analysis for the pooled data set yields RR: $0.64,95 \%$ CI 0.55 to $0.75, \mathrm{p}<0.05$.

\section{Self-care behaviour}

Self-care behaviour, as measured with EHFScB-9, improved significantly from baseline to follow-up after 180 days, in the IG. At baseline the score, reported as (median; inter-quartile range), was (30; 26-35) and after 180 days it was $(22 ; 16-27)$, that is, an improvement by $27 \%$ or eight points, $\mathrm{p}<0.05$. The validated subscale of the EHFScB, called consulting behaviour, which indicates a patient's propensity to call his/her HCP in case of worsening symptoms, also showed significant improvement, as it went from $(16 ; 12-20)$ at baseline, to $(13 ; 7-18)$

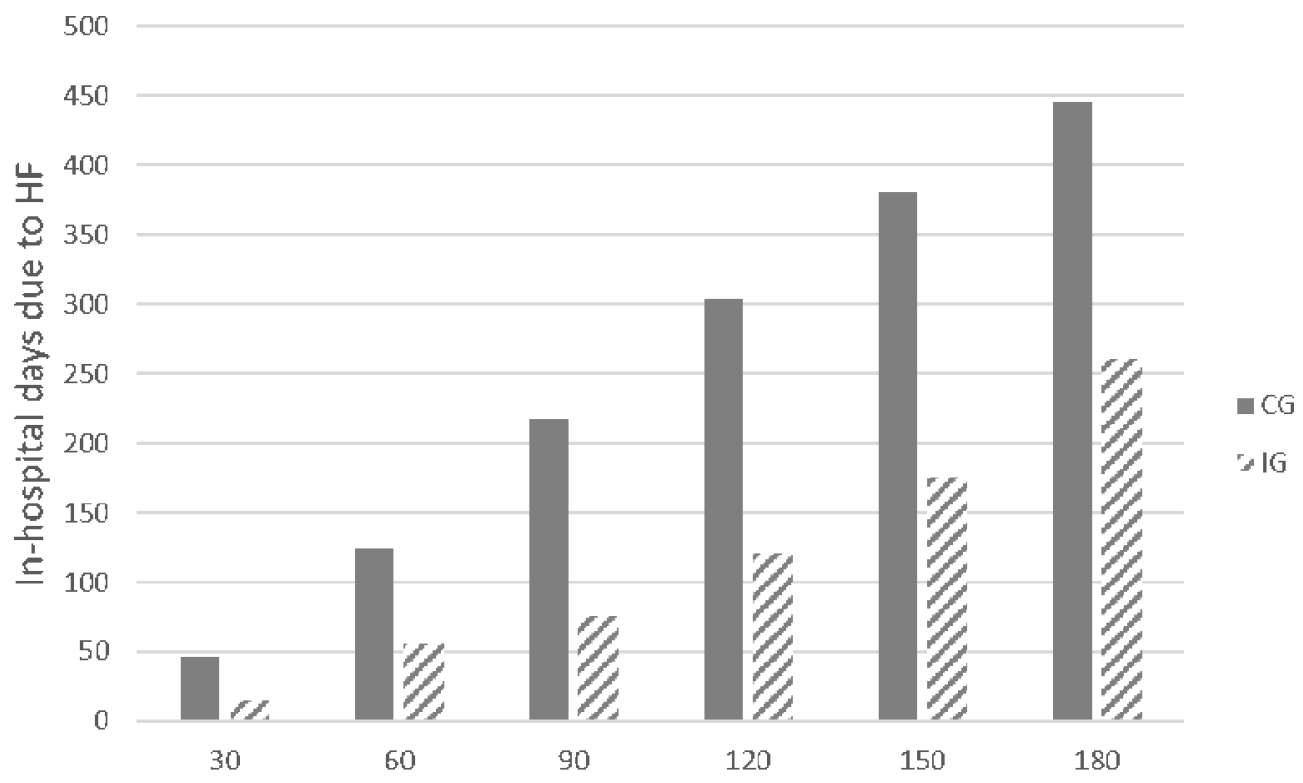

Days after randomisation

Figure 2 HF related in-hospital days over time. CG, control group; HF, heart failure; IG, intervention group. 
after 180 days, which is an improvement by $19 \%$ or three points, $\mathrm{p}<0.05$.

\section{Adherence to the mHealth-tool}

The adherence to the HF-tool, was defined as the number of days the patient interacted with the mHealth-tool in any way (reading information, weighing themselves or reporting symptoms), divided by the number of days they had been equipped with the tool. Out of the 82 patients equipped with the tool, complete data recorded in the tool for the 180 days was available for 65 patients (79\%). The median system adherence was (94\%: 84\%-98\%). The multiple linear regression analysis yields that neither age nor gender have a statistically significant influence on the adherence and the effect sizes were also small $(4 \%$ and $0.4 \%$ for age and gender, respectively). Whether a patient lived in a rural or urban area was, however, statistically significant, with an effect size of $17 \%(\mathrm{p}<0.05)$, in favour of patients living in rural areas.

\section{DISCUSSION \\ In-hospital days}

The effect on in-hospital days in the Hemse study was similar to that in the PACEMAN-HF study, and the pooled and adjusted analysis also produced a significant result. The effect size reported herein is similar to what has been previously reported in studies where education, weight and/or symptom monitoring diaries and telephone support has been evaluated. Cline et al showed a non-significant ( $\mathrm{p}=0.07$ ) reduction of in-hospital days by $49 \%$ (or 4.0 days) as a result of an intervention where a weight and symptom diary was used together with a flexible diuretics regimen, as well as education sessions. ${ }^{22}$ Doughty et al reported a $38 \%$ reduction (or 2.2 days) as a result of a similar intervention. ${ }^{3}$ In a study of a nurse led outpatient HF clinic, Strömberg et al, showed a $64 \%$ reduction of in-hospital days (or 2.5 days) over a 12-month period and the corresponding number reported after 3 months was $45 \% .{ }^{23}$ While these other interventions all included counselling with an actual HF nurse, the investigated mHealth-tool was fully automatic, which might explain the smaller effect size. After this study was performed, a non-randomised controlled clinical intervention study was performed by Norrtälje hospital (Sweden), evaluating the effect of the mHealth-tool on their HF population. The findings have not been published in a peer-reviewed journal, but as an abstract at the ESC HF congress in Paris, 2017. That study showed similar results as this study, and they found a reduction of in-hospital days compared with the CG, by $36 \%$ after 9 months. ${ }^{24}$

\section{Self-care behaviour and adherence}

The changes in self-care behaviour, as measured with the EHFScB-9 are similar to findings from Pulignano et al, who reported a difference of eight points as an effect of attending a HF clinic, but a larger effect than what was seen in other studies. ${ }^{23} 25-27$ The tool was designed for elderly patients and patients with multiple comorbidities and has the advantage of being accessible whenever the patient is ready to seek information, as well as being part of every-day routines. The way information is packaged and delivered matters greatly in terms of the actual uptake of knowledge, and the tool was constructed according what was suggested by Coulter in order to be pedagogic and user-friendly for this particular population..$^{28}$ Another explanation of the positive results in this present study, might be the very high adherence to the tool, which to our knowledge is the highest reported system adherence

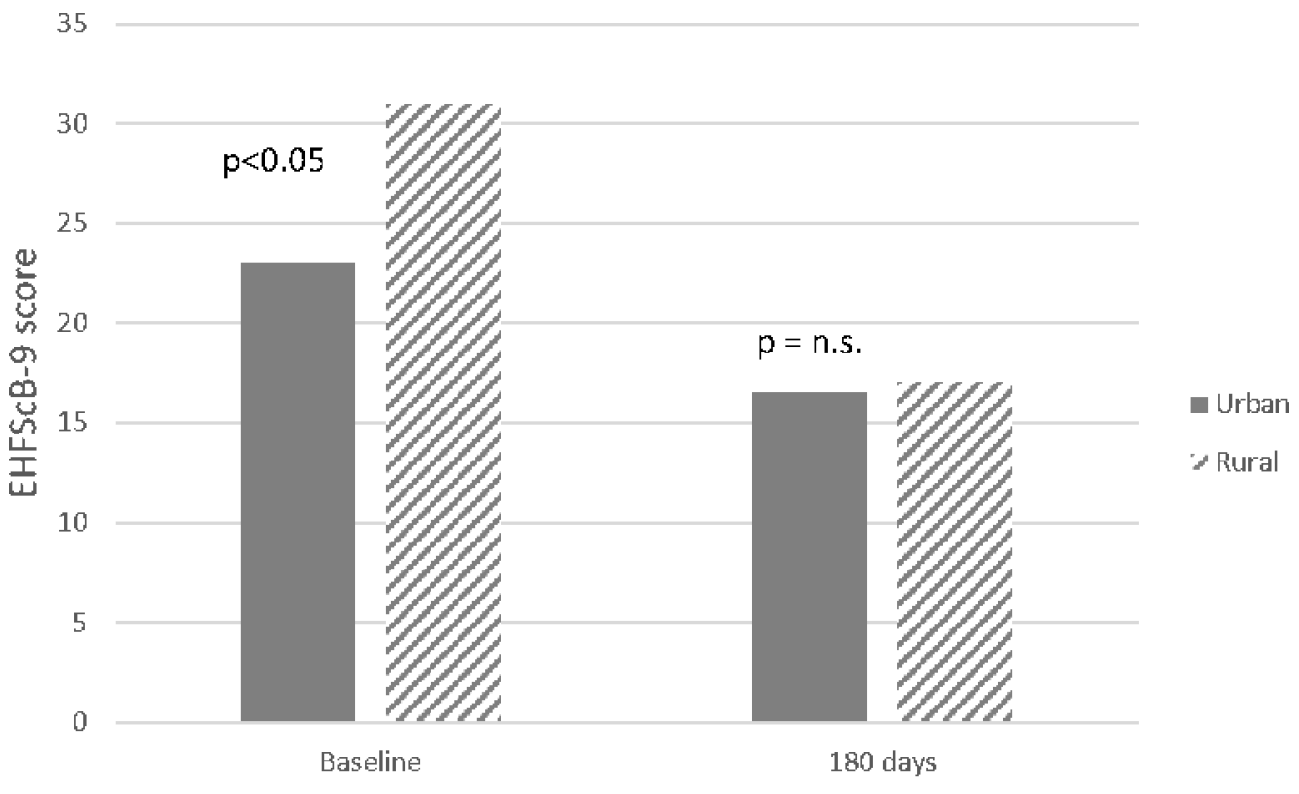

Time

Figure 3 Self-care behaviour as EHFScB-9 score at baseline and after 180 days. EHFScB, European Heart Failure Self-care Behaviour; HF, heart failure; n.s., non-significant. 
to a home-based system after 180 days for HF patients. The fact that neither age nor gender predicted the level of adherence, is a positive trait of the mHealthtool, as patient involvement is important in behavioural change. ${ }^{29}$ Furthermore, the means by which the patient is engaged should be tailored, and the mHealth-tool adjusts what educational material is being shown, based on how the patient interacts with the system. ${ }^{30}$ It has also been described that access to outpatient HF clinics is less common for patients in rural areas, so the finding that patients in rural areas tend to have a higher adherence to the mHealth-tool is encouraging, as it is important that these patients also gain access to the same information and education as patients in urban areas. ${ }^{31}{ }^{32}$ Although speculative, the reason for the higher adherence to the mHealth-tool could be that patients tend to follow 'doctor's orders' to a greater extent in rural areas. We also have anecdotal information from coworkers indicating a tendency towards 'care-shopping' in the capital region of Stockholm, where patients actively seek out different HCPs to for comparison purposes, whereas in the rural communities, patients will to a greater extent always see the same doctor and therefore also develop greater trust and confidence. We believe this might also influence the adherence to prescribed treatment and recommendations. The data from this current study confirms that a poorer self-care behaviour is present in the rural area, compared with the urban areas and an interesting finding is that while there was a significant difference in self-care behaviour between the two cohorts at baseline, that difference disappeared after being exposed to the intervention for 180 days, and both cohorts displayed significant improvement (see figure 3).

\section{Limitations of the study}

The Hemse-study was designed to be a realistic real-world implementation of the PACEMAN-HF study, and the analyses herein were intended to explore the external validity, or generalisability of the existing findings about the HF-tool. There are several limitations to both studies and also to this pooled analysis, which should be emphasised. Even though it was key to the entire research project to recruit patients from different settings, it should be noted that the treatment, health status and self-care behaviour were significantly different between the two cohorts at baseline. In the PACEMAN-HF cohort, $74 \%$ were NYHA class III compared with $43 \%$ in the Hemse cohort. Only $74 \%$ of patients in the PACEMAN-HF cohort were receiving RAS-blockade, with the corresponding number in the Hemse cohort being 93\%. This difference in treatment and health status probably explains why close to $86 \%$ of the HF-related in-hospital days originated from the PACEMAN-HF cohort, but another factor that could influence this difference is that all patients in the Hemse cohort had attended a specialised outpatient HF-clinic, which the patients in PACEMAN-HF had not. Both studies have, however, reported statistically significant results individually before, and the adjusted statistical model was introduced to mitigate the effects of this discrepancy. Furthermore, all patients had a confirmed HF diagnosis, the gender distributions were similar with $68 \%$ versus $65 \%$ male for PACEMAN-HF and Hemse, respectively, and age distributions were also similar although the Hemse-patients were on average 3 years older, with mean ages $78 \pm 9$ versus $75 \pm 8$. Once the data sets were pooled, statistically significant differences in prevalence of HTN, as well as beta-blockade treatment appeared. This could suggest that the CG was under treated and any effect might a least in part be attributed to suboptimal medical treatment. However, beta-blockers are not the first choice of treatment for hypertensive patients, and therefore this may be a manifestation of well-motivated clinical practise. In recent years, new evidence has been published to suggest a positive association between use of beta-blockers for HF patients with hypertensive aetiology and this might get an increasing role in treating these patients. ${ }^{33}$ The differences in pharmacological treatment, as well as the age-difference, could be a sign of a higher prevalence of HF with preserved ejection-fraction in the Hemse-cohort. It is a limitation that no self-care data were collected from the CG in the Hemse-study, which could have added statistical power to the findings presented herein relating to the EHFScB-9.

\section{CONCLUSION}

We claim that the Hemse-study, with its similarities and differences to PACEMAN-HF, adds a valuable piece to the puzzle, when trying to ascertain whether the investigated mHealth-tool might be relevant for a wider group of HF patients in a general setting, and second, that it adds to the body of knowledge in this field to perform a pooled analysis. Our conclusion is that the mHealth-tool, primarily through its ease of use and successful means of getting through to the patient, can be an asset in current HF treatment and may be a way to assist in providing equal care to patients in rural areas or without access to outpatient HF clinics.

Contributors All listed authors have participated in patient recruitment, data collection, data analysis and as manuscript writing/review.

Funding The Hemse-study was financed by Region Gotland.

Competing interests None declared.

Patient consent for publication All patients have given informed consent to participate in the study.

Ethics approval The research conducted adhere to the ethical principles of the Declaration of Helsinki and the study was approved by the Regional Ethical Review Board in Sweden.

Provenance and peer review Not commissioned; externally peer reviewed.

Data sharing statement All data relevant to the study are included in the article or uploaded as supplementary information.

Open access This is an open access article distributed in accordance with the Creative Commons Attribution Non Commercial (CC BY-NC 4.0) license, which permits others to distribute, remix, adapt, build upon this work non-commercially, and license their derivative works on different terms, provided the original work is properly cited, appropriate credit is given, any changes made indicated, and the use is non-commercial. See: http://creativecommons.org/licenses/by-nc/4.0/. 


\section{REFERENCES}

1. World Health Organization. mHealth: new horizons for health through mobile technologies: second global survey on eHealth, ISBN: 97892 4156425 0, 2011.

2. Seferović PM, Stoerk S, Filippatos G, et al. Organization of heart failure management in European Society of cardiology member countries: survey of the heart Failure Association of the European Society of cardiology in collaboration with the heart failure national Societies/Working groups. Eur J Heart Fail 2013;15:947-59.

3. Doughty RN, Wright SP, Pearl A, et al. Randomized controlled trial of integrated heart failure management. Eur Heart J 2002;23:139-46.

4. Stewart S, Jenkins A, Buchan S, et al. The current cost of HF to the NHS in the UK. Eur J Heart Fail 2002;4:361-71.

5. Bloom DE, Chatterji S, Kowal P, et al. Macroeconomic implications of population ageing and selected policy responses. The Lancet 2015;385:649-57.

6. Braunwald $\mathrm{E}$. The war against heart failure: the Lancet lecture. The Lancet 2015;385:812-24.

7. Ledwidge M, Barry M, Cahill J, et al. Is multidisciplinary care of heart failure cost beneficial? Eur J Heart Fail 2003;5:381-9.

8. Powell LH, Calvin JE, Richardson D, et al. Self-management counseling in patients with heart failure: The heart failure adherence and retention randomized behavioral trial. JAMA 2010;304:1331-8.

9. Chalkidou K, Tunis S, Whicher D, et al. The role for pragmatic randomized controlled trials ( $\mathrm{pRCTs}$ ) in comparative effectiveness research. Clin Trials 2012;9:436-46.

10. Treweek S, Zwarenstein M. Making trials matter: pragmatic and explanatory trials and the problem of applicability. Trials 2009;10.

11. Delitto A. Pragmatic clinical trials: implementation opportunity, or just another FAD? Phys Ther 2016;96:137-8.

12. Fonseca C. Diagnosis of heart failure in primary care. Heart Fail Rev 2006;11:95-107.

13. Persson $\mathrm{H}$, Erntell $\mathrm{H}$, Eriksson $\mathrm{B}$, et al. Improved pharmacological therapy of chronic heart failure in primary care: a randomized Study of NT-proBNP Guided Management of Heart Failure--SIGNAL-HF (Swedish Intervention study--Guidelines and NT-proBNP AnaLysis in Heart Failure). Eur J Heart Fail 2010;12:1300-8.

14. Hägglund $E$, Lyngå $P$, Frie F, et al. Patient-centred home-based management of heart failure. Scandinavian Cardiovascular Journal 2015;49:193-9.

15. Melin M, Hägglund E, Ullman B, et al. Effects of a tablet computer on self-care, quality of life, and knowledge: a randomized clinical trial. $J$ Cardiovasc Nurs 2018;33.

16. Hovland-Tånneryd A, Hägglund E, Ullman B, et al. PACEMAN-HF pooled analysis from two randomized controlled trials. Eur $J$ Heart Fail 2016;18(Suppl. 1).

17. McMurray JJ V, Adamopoulos S. Anker S D, et al. ESC guidelines for the diagnosis and treatment of acute and chronic heart failure 2012: the task Force for the diagnosis and treatment of acute and chronic heart failure 2012 of the European Society of cardiology. developed in collaboration with the heart Failure Association (HFA) of the ESC Eur J Heart Fail 2012;33:1787-847.

18. Jaarsma T, Årestedt KF, Mårtensson J, et al. The European heart failure self-care behaviour scale revised into a nine-item scale (EHFScB-9): a reliable and valid international instrument. Eur $J$ Heart Fail 2009;11:99-105.

19. Jaarsma T, Cameron J, Riegel B, et al. Factors related to self-care in heart failure patients according to the middle-range theory of self-care of chronic illness: a literature update. Curr Heart Fail Rep 2017;14:71-7.

20. Li H, Wang L, Wei L, et al. Sample size calculation for count data in comparative clinical trials with nonuniform patient accrual and early dropout. J Biopharm Stat 2015;25:1-15.

21. Thabane L, Kaczorowski J, Dolovich L, et al. Reducing the confusion and controversies around pragmatic trials: using the Cardiovascular health awareness program (CHAP) trial as an illustrative example. Trials 2015;16.

22. Cline CM, Israelsson BY, Willenheimer RB, et al. Cost effective management programme for heart failure reduces hospitalisation. Heart 1998;80:442-6.

23. Strömberg A, Mårtensson J, Fridlund B, et al. Nurse-led heart failure clinics improve survival and self-care behaviour in patients with heart failure: results from a prospective, randomised trial. Eur Heart $J$ 2003;24:1014-23.

24. Blomqvist A, Sjostrom K, Ohman E, et al. Evaluation of e-health tool for heart failure patients [abstract]. Eur J Heart Fail 2017;19(Suppl. S1).

25. Pulignano G, Del Sindaco D, Minardi G, et al. Translation and validation of the Italian version of the European heart failure self-care behaviour scale. J Cardiovasc Med 2010;11:493-8.

26. Peters-Klimm F, Campbell S, Hermann K, et al. Case management for patients with chronic systolic heart failure in primary care: the HICMan exploratory randomised controlled trial. Trials 2010;11.

27. Köberich S, Glattacker M, Jaarsma T, et al. Validity and reliability of the German version of the 9-item European heart failure self-care behaviour scale. Eur J Cardiovasc Nurs 2013;12:150-8.

28. Coulter A. Patient engagement--what works? J Ambul Care Manage 2012;35:80-9.

29. Grol R. What drives change? Barriers to and incentives for achieving evidence-based practice. Med J Aust 2004;180(6 Suppl):57-60.

30. Strömberg A. The crucial role of patient education in heart failure. Eur J Heart Fail 2005;7:363-9.

31. Verdejo HE, Ferreccio C, Castro PF. Heart failure in rural communities. Heart Failure Clinics 2015;11:515-22.

32. Vasko P, Ros I. Inför hjärtsviktsmottagning på vårdcentralen, 2016. Available: https://www.dagensmedicin.se/artiklar/2016/12/21/inforhjartsviktsmottagning-pa-vardcentralen/ [Accessed 02 Oct 2018].

33. Lund LH, Benson L, Dahlström U, et al. Association between use of $\beta$-blockers and outcomes in patients with heart failure and preserved ejection fraction. JAMA 2014;312:2008-18. 